\title{
Impact of Length of Stay on both Financial Health and Medical Outcomes of Mission Hospitals in Rural Ghana
}

\author{
Ebenezer Kenneth Abban \\ Healthcare Administration, Texila American University, Akwatia, Ghana
}

\begin{abstract}
One of the major key clinical indicators of hospital performance is length of stay (LOS). This denominator is calculated in averages. The role of this measure could be dual (as medical outcome or financial health indicator). Regardless, it can also be observed as either positive or negative variable depending on how it is measured. By this study, LOS was assessed on both counts: as a measure of financial health and also as medical outcome of hospital. The investigator concludes, after thorough evaluation of available data, from both structured interviews and responses to a set of questions in a survey, that truly length of stay impacts positively on medical outcomes and also could be a measure of the financial healthiness of hospital.
\end{abstract}

Keywords: Financial Healthiness, Financial Health, Hospital, Length of Stay, Medical Outcomes.

\section{Introduction}

Length of stay (LOS) is an important indicator of the efficiency of hospital management. Reduction in the number of inpatient days results in decreased risk of infection and medication side effects, improvement in the quality of treatment, and increased hospital profit with more efficient bed management [1]. This indicator is often used to measure the number of days a patient spends on the hospital bed accessing treatment, thus, between the day of admission and the day of discharge [2]. It is a measure of profitability in the financial ratios of health indicators. It is assumed that the more patient spends days on the bed receiving treatment, the likelihood that more medical consumables are used and the risk of infection with other diseases are heightened.

Inpatient care is estimated to make up about one-third of the entire healthcare expenditures in the United States [3]. This clearly represents a significant impact on the country's economy. Length of stay (LOS) is one aspect of output of care that could be very expensive to bear by most healthcare systems. The right approach and strategies are always required to forestall the telling cost that could be accumulated in this regard. Pezzani, in a study titled patient-centered LOS reduction initiative, improves outcomes and saves cost, indicated that U.S. hospital length of stay costs the health system at least $\$ 377.5$ billion per year.

"In today's value-based care environment, hospitals are under increasing pressure to avoid patient harm and maintain quality while also lowering costs. Reducing hospital length of stay (LOS), especially as it relates to avoiding unnecessary hospital-acquired conditions (HACs), is a primary indicator of a hospital's success in achieving these goals" [4].

Managing LOS at the hospital could be profitable as it shall reduce cost and improve medical outcomes [5]. It is obviously the case that, as patients spend more time at the hospital, there is the likelihood for infections to be contracted. Usage of medical consumables certainly shall be in higher proportion, and care for patients could be time-consuming. While Length of Stay improves patient safety and lowering costs, mitigating LOS can create more capacity within the system (including beds and 
staff time) and improve throughput, enabling the hospital to serve more patients. Reducing LOS impacts cost and outcomes [6].

Studies, however, have found a positive correlation between shorter LOS and risk of readmission of patients and sometimes even mortality resulting from pulmonary embolism complications. Sicker patients tend to stay longer in hospitals.

"In a study on mortality, researchers compared mortality rates at a single medical center for admitted patients who were assigned to physicians that tended to have long versus short LOS admissions. In a sample of over 12,000 admissions, patients receiving care from short LOS physicians had a significantly increased risk of 30-day mortality relative to propensity-score matched patients receiving care from long LOS physicians. This suggests that policies incentivizing shorter lengths of stay may be associated with worse patient outcomes" in the long run [7].

Given the operational efficiency associated with reduced LOS at hospitals, many healthcare organizations are invariably interested in reducing LOS. Although it is a mechanism necessary for profitability and improvement in medical outcomes [8], ensuring reduction in LOS carries a lot of burdens, and to effect, such change could be very daunting because of the complex and multi-layered nature of the phenomenon involved in reducing LOS at hospitals [9]. Several departments, units, and disciplines are required to interplay roles in this solution-oriented processes. Several studies have identified a range of patient characteristics and clinical predictors contributing to longed LOS, including age, sex, delayed access to health care, inaccuracy of data, disease severity, presenting conditions, and complications.

Although a team-based approach to hospital care management could be very challenging, adoption of the latter may be the way out to leverage the system advantage of LOS. Due to lack of requisite training, frontline staff may find it difficult to appropriately track and assign patient's status at the point of entry, which could affect plans for admission discharges. Similarly, lack of regular communication between financial and clinical departments can result in knowledge gaps with respect to financial regulations and contract requirements that may lead to costly forfeitures [10]. Additionally, convincing physicians to work on reducing the length of stay can be difficult without actionable data that links improvements in the quality of patient care with financial goals. Consequently, initiatives in staff continuous training aimed at execution of coordinated care management on team bases must be encouraged. This has the potential to addressing several bottlenecks associated with long LOS and to make impactful efforts in addressing organizational continuous improvement performance [11].

The average length of stay (ALOS) refers to the average number of days that a patient spends in the hospital. It is generally measured by dividing the total number of days stayed by all inpatients during a year by the number of admissions or discharges. The Average Length of Stay according to Organization for Economic Cooperation Development (OECD) for the Europe Area, including countries like Netherland, Spain, Germany, Italy, France, Finland, Austria, Ireland, Belgium, Portugal, among others, stood at 6.5 days for the year ending 2020. For the same period, the G7 countrie's average length of stay stood at 7.9 days and 5.5 days for the United States of America [12], although another study by Bakkum, put ALOS in the US across all states between 5.8 and 6.4 days with the National average at 4.5 days. Nonetheless, discharges occur purely based on the cases presented by patients. In a study conducted by [1] overall, $55 \%(25,228)$ of inpatients who were discharged within 4 days presented with mild to acute conditions.

"The department of rehabilitation medicine (RH) had the highest average LOS at 15.9 days. Of all the conditions diagnosed over 250 times, diagnoses of I63.8 (cerebral infarction, middle 
cerebral artery), 163.9 (infarction of middle cerebral artery territory), and 121.9 (myocardial infarction) were associated with the longest average hospital stay and high standard deviation".

A deeper look at the extent to which length of stay plays this dual role of being a measure of the financial health of hospital and also an indicator of medical outcome was evaluated by the investigator on the hypothesis: Ho (null): $\mu \mathrm{A}$ - $\mu \mathrm{c}=\mathrm{O}$ Length of stay does not influence financial health and medical outcomes of hospitals. Ha (alter): $\mu \mathrm{A}-\mu \mathrm{c}=\varnothing$ Length of stay does influence financial health and medical outcomes of hospitals.

\section{Methodology}

In an attempt to address the topic, the Quantitative (structured) research approach as [13], proposes was used. Structured interview method with senior accountants and health information officers based on eleven closedended questions, and survey of 1350 health workers, i.e., health information officers, accountants, medical doctors, physician assistants, nurses, laboratory scientists, biomedical engineers, estate workers, orderlies, and administrative staff, via the administration of eighty-seven ordinal and eleven nominal questions questionnaire, were employed throughout those mission hospitals.

Respondents were asked to answer 5-point Likert scale questions regarding financial health and medical outcomes as the dependent variables with the length of stay as the independent variable. The annual performance review data of the hospitals were accessed via interview sessions with health information officers, and averages were determined on trend analysis over ten years period using a simple excel spreadsheet to form an idea about the medical outcomes of the hospitals based on output within the periods under study. Additionally, senior accountants were interviewed on the financial positions of the respective hospitals while emphasizing the length of stay during those times $(2018,2019$ \& 2020), relying on the audited financial statements for those years [14].

\section{Study Type}

A cross-sectional study design, via structured interviews, focused on trend analysis of collected, reliable, and available data over a period of ten and three years. Perceptions of the respondents of the administered questionnaire were also gathered by the data collected.

\section{Population and Sample Size}

Sample size $(\mathrm{n})=\mathrm{N} /\left[1+\mathrm{N}\left(\mathrm{e}^{2}\right)\right]$

Where; $\mathrm{n}=$ Sample Size, $\mathrm{N}=$ Total population, $\mathrm{e}=$ margin of error $(5 \%$ or 0.05$)$ with confidence level of $95 \%$.

- 1350 health workers. Refer Table 1.

Table 1. Sample size

\begin{tabular}{|l|l|l|}
\hline Facilities & Staff Population & Sample size (n) \\
\hline Hospital 1 & 687 & 253 \\
\hline Hospital 2 & 484 & 219 \\
\hline Hospital 3 & 620 & 243 \\
\hline Hospital 4 & 286 & 167 \\
\hline Hospital 5 & 218 & 141 \\
\hline Hospital 6 & 238 & 149 \\
\hline Hospital 7 & 320 & 178 \\
\hline Total & 2853 & 1350 \\
\hline
\end{tabular}

Source: Ryan, (2013) 


\section{Data Collection and Tools}

The investigator utilized structured interviews and administration of questionnaire in a survey to collect and gathered the required data. Data were entered into open-source software - epidata. The data were later exported to 'Stata 15 ' software for analysis.

In the interviews, participants of the study were asked questions bothered on the financial health, medical outcomes, and length of stay of the hospitals over a period of three years and ten years. Questions on the financial health of the hospitals based on the financial position statements of the hospitals for the previous three years $(2018$ - 2020) were asked, and financial ratios were calculated in a word document table. The data on annual clinical indicators for ten years $(2011$ - 2020) were entered onto a simple excel spreadsheet to determine the averages of average length of stay. Additionally, respondents of the questionnaire were made to answer 5-point Likert scale questions on the financial performance, medical outcomes, and length of stay of the hospitals.

\section{Data Analysis}

Applying financial ratios, namely, profitability, liquidity, and operating efficiency, a close assessment of the financial health of the mission hospitals for a three-year period (20182020) using the year ending audited financial statements was done. Also, based on the parameters set by [15], trend analysis of length of stay to determine the average over a period of ten years was done to measure the medical outcome of the mission hospitals via a simple excel spreadsheet. These analyses were done subsequent to the structured interviews with health information officers.

Additionally, 'Stata 15' was employed in the analysis of the data gathered from the responses to the questionnaire. The data was analyzed in descriptive, regression, and hypothesis to establish the veracity or otherwise of the topic.

\section{Variables Measurement}

Refer Table 2.

Table 2. Variables Measurement

\begin{tabular}{|l|l|}
\hline \multicolumn{2}{|l|}{ Table of variables measurement } \\
\hline Dependent variable & Financial health and medical outcomes of hospital \\
\hline Independent variables & Length of stay \\
\hline
\end{tabular}

Source: Field work, 2021

\section{Results and Discussions}

Truly, the financial health of hospitals mainly influences medical outcomes. In the study commissioned by the World Bank, [16] concluded that in Ghana at the time, the overall hospital attendance trend based on the National Health Insurance Scheme (for most categories) were extremely progressive. Occupancy rates had increased from $45 \%$ to around $60 \%$, and average lengths of stay had decreased from 4.5 to 3.8 days. This study found that, in line with the study as quoted, because the financial health of the hospitals were generally appreciable, medical outcomes were correspondingly significant. There were enough reasons to rely on the hypothesis that length of stay impacts financial health and medical outcomes (refer Table 3). Along with other staring findings, the profitability, liquidity, and operating efficiency ratios of the hospitals were admirably positive. Thus, financial health is largely impacted by the medical outcomes (length of health) of the mission hospitals. 
Table 3. Simple Linear Regression showing the Effect of Length of Stay on Financial Health and Medical Outcomes of Mission Hospitals

\begin{tabular}{|l|l|l|l|l|}
\hline Covariate & Coefficient & Standard Error & p-value & 95\% CI \\
\hline Length of Stay (LOS) & 0.02 & 0.01 & $0.008^{*}$ & {$[0.01-0.04]$} \\
\hline
\end{tabular}

Statistically significant at $\mathrm{p}<0.05^{*}$

CI - Confidence Interval

Adjusted R-squared $=0.0044$

Hypothesis

Reject $\mathrm{H}_{0}$ and conclude on $\mathrm{H}_{1}$

\section{Profitability of the Hospitals}

The ability of the hospitals to generate earnings relative to revenue, operating costs, balance sheets assets and/or shareholders' equity over time was measured using the profitability ratios. Return on Capital Employed (a measure of the Hospitals profitability in terms of all its capital); Net Profit Margin (net profit expressed as a percentage of sales or revenue) and Asset Turnover (a measure of how well the assets of the hospitals were used to generate sales) were the few metrics used to measure how profitable the Hospitals were over the period under review.

The results of the analysis showed that with the exception of the Assets Turnover, which had been on the rise from 2018, the two other ratios reached their highest in 2019 before declining in 2020. Even though there was a decline, the values in 2020 still looked better than the values in 2018 .

For instance, for every capital that the Hospitals employed in 2020, 5.25\% was generated into operating profit or surplus. This was to earn every cedi the hospitals needed to employ GH $\not 19.05\left(\frac{100}{5.25}\right)$ Worth of capital. The hospitals also earned 3.10 pesewas on every cedi collected as revenue. The Hospitals, on average used Assets, 1.69 times to generate sales.

The indicators of the Hospitals' profitability were very encouraging. The Hospitals kept improving on their performance over the years.

\section{Liquidity of the Hospitals}

Liquidity refers to the ease with which an asset can be converted into ready cash. It is the ability of the Hospitals to pay off their debt obligations to measure the Hospitals' liquidity. Current Ratios (a measure of current assets against current liabilities) and Acid Test or Quick Ratio were calculated.

There had been improvement in the Hospitals' ability to settle their current liability from their current assets. The current ratio, for instance had been improving over the years, rising from $2.35: 1$ in 2018 to $3.4: 1$ in 2020 . The Quick/Acid Test Ratio had also been improving, increasing from 1.73:1 in 2018 to 2.66:1 in 2020.

The results of the liquidity ratios calculated gave an indication that the Hospitals were in good financial health and were less likely to face financial hardships. The Liquidity position of the Hospitals was very good; hence they were able to pay of their short-term liabilities when they were use.

\section{Operating Efficiency of the Hospitals}

Efficiency ratios measure the Hospitals' ability to use its assets and manage its liabilities effectively in the current period or short term [17].

The Hospitals' ability to use their assets and manage their liabilities effectively in the current period or short term was measured using the efficiency ratios (Receivables Days Ratio, Payable Days Ratio, Average Inventory Turnover Period, and Cash Conversion Cycle). The results of the analysis gave an indication that the Hospitals had been efficient in their debt collection, reducing from 83.56 days in 2018 to 74.62 days in 2020.

The Hospitals had also been improving on the number of days it took them to pay off their suppliers, decreasing from 237 days in 2018 to 152 days in 2020. The rate at which the Hospitals sold and replaced stock of goods had also improved over the period, decreasing from 176 days in 2018 to 115 days in 2020. 
These ratios put together helped to determine how much time the Hospitals took to sell their inventory, how much time they took to collect receivables, and how much time it took the hospitals to pay their bills. The results from the cash conversion cycle gave an indication that the Hospitals did not need operating cash to grow. Their operations were financed mostly by their suppliers.

In conclusion, the state of the Hospitals' financial situation looked very good over the period under discussion. There was a steady rise in profitability, liquidity position, and operating efficiency. The Hospitals, on average had an improved profitability level, improved liquidity position, and improved operating efficiency.

Referencing the benchmarks of the European areas, the national average of Ghana for the length of stay as found by the World Bank study (2012) was 7 days. Reflecting on the trend analysis of data of the mission facilities for a tenyear period showed a downward trend of the length of stay at the mission hospitals.

Although the downward trend of the length of stay could have a positive correlation with profitability and reduced cost of operations, thus, the sound financial health of the latter, it also could be associated with a high rate of readmissions and even mortality in some cases [8]. Additionally, hospitals could make a lot of expenditures on longer lengths of stays. Therefore, the shorter the average length of stay, the better.

The result as shown by figure 1 , indicates the downward trend of the length of stay over the period at $4.78 \%$. Clearly, the mission hospitals did very well over the period since reducing the length of stay (Gilbert, 2015) is a multi-facet endeavor.

\section{Length of stay 2011-2020}

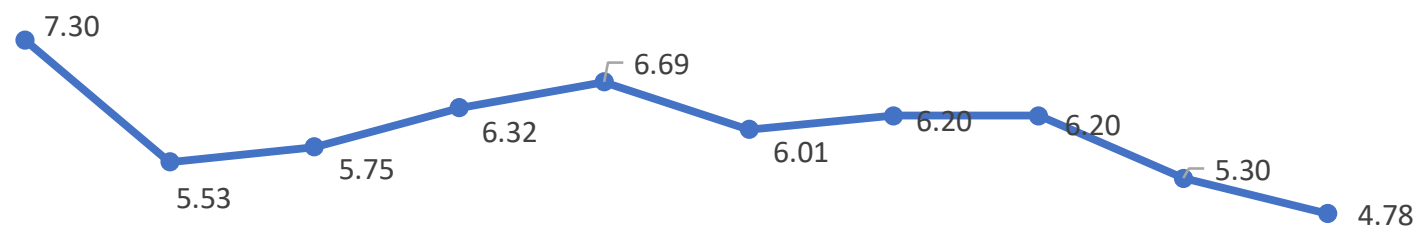

ANNUAL ANNUAL ANNUAL ANNUAL ANNUAL ANNUAL ANNUAL ANNUAL ANNUAL ANNUAL $\begin{array}{llllllllll}2011 & 2012 & 2013 & 2014 & 2015 & 2016 & 2017 & 2018 & 2019 & 2020\end{array}$

Source: Field work, 2021

Figure 1. Length of Stay 
Table 4. Results for the Descriptive Statistics, Scale and Item Reliability Test of the Variables

\begin{tabular}{|l|l|l|l|l|l|}
\hline \multirow{2}{*}{ Dimensions } & \multirow{2}{*}{$\begin{array}{l}\text { Number } \\
\text { of items }\end{array}$} & $\begin{array}{l}\text { Cronbach's } \\
\text { Alpha } \\
\text { Coefficient }\end{array}$ & \multicolumn{3}{|l|}{ Health Professionals (n=1356) } \\
\cline { 5 - 6 } & & & Mean & $\begin{array}{l}\text { Standard } \\
\text { Deviation }\end{array}$ & $\begin{array}{l}\text { Mean Values under } \\
\text { 95\% Confidence } \\
\text { Interval }\end{array}$ \\
\hline $\begin{array}{l}\text { Financial Health and } \\
\text { Medical Outcome (Overall) }\end{array}$ & $\mathbf{9}$ & $\mathbf{0 . 8 6 3}$ & $\mathbf{3 . 3 5}$ & $\mathbf{0 . 0 2}$ & {$[\mathbf{3 . 3 1}-\mathbf{3 . 3 8}]$} \\
\hline Financial performance & 5 & 0.847 & 3.15 & 0.02 & {$[3.11-3.20]$} \\
\hline Medical outcomes & 4 & 0.817 & 3.59 & 0.02 & {$[3.55-3.63]$} \\
\hline $\begin{array}{l}\text { Average Length of Stay (in } \\
\text { Days) }\end{array}$ & $\mathbf{1}$ & & $\mathbf{4 . 8 1}$ & $\mathbf{0 . 0 7}$ & {$[\mathbf{4 . 6 8}-\mathbf{4 . 9 4}]$} \\
\hline
\end{tabular}

Source: Fieldwork, 2021

\section{Conclusion}

Length of stay, depending on how it is appreciated, could make a lot of impact on the financial health and medical outcomes of the hospital. The study has proven this assertion to be true in the case of the hospital assessed; the financial position statements for three years on a row indicated that while the length of stay went down, financial health was equally good. The same was true from the perceptions of respondents as reflected in the regression analysis (causal effect) of the data collected. gathered from Managers of hospitals may pay

\section{References}

[1] Baek H, Cho M, Kim S, Hwang H, Song M, Yoo S (2018) Analysis of length of hospital stay using electronic health records: A statistical and data mining approach. PLoS ONE 13(4): e0195901. https://doi.org/10.1371/journal.pone.0195901.

[2] Segen's Medical Dictionary. (2011). Length of stay. (n.d.). Retrieved June 7, 2021, from https://medical-

dictionary.thefreedictionary.com/length+of+stay.

[3] Dennis O’Hare, (2016). How Allina saved $\$ 13$ million by optimizing LOS. Available at How Allina Saved \$13 Million By Optimizing LOS (healthcatalyst.com) and retrieved on 18/07/2021.

[4] Michelle Pezzani, (2016). Patient-centered LOS reduction initiative improves outcomes, save cost. Available at Patient-Centered LOS Reduction particular attention to how long patients spend on beds in their facilities.

\section{Conflict of Interest}

The principal investigator declares that there is no conflict of interest.

\section{Acknowledgment}

I would like to sincerely thank Professor Peter Agyei-Baffour for his guidance in this investigation. Also, I wish to thank Godwin Adzakpah and Richard Ahorlu, CA, for their inputs in this study.

Initiative Improves Outcomes, Saves Costs (healthcatalyst.com) and retrieved on 19/07/2021.

[5] Melody Griffith (2018). Reducing the length of stay impacts cost and outcomes. Retrieved 08/07/2021 and available at https://www.healthcatalyst.com/success_stories/redu cing-length-of-stay-memorial-hospital-at-gulfport/.

[6] Lance Robinson, (2020). Care management and reducing average the length of stay: connecting the dots. Retrieved on 18/07/2021 and available at https://www.kaufmanhall.com/insights/article/caremanagement-and-reducing-average-length-of-stay. [7] Gilbert, J. (2015). Hospital readmissions and length of stay. The Incidental Economist available at http://theincidentaleconomist.com/wordpress/hospita 1-readmissions-and-length-of-stay/andretrieved on 19/07/2021. 
[8] Ong, M. S., Magrabi, F., \& Coiera, E. (2018). Delay in reviewing test results prolongs hospital length of stay: a retrospective cohort study. BMC health services research, 18(1), 369. Retrieved on $18 / 07 / 2021$ and available at https://www.ncbi.nlm.nih.gov/pmc/articles/PMC595 6538.

[9] Shawn Melvin, (2019). Steps to improving length of stay: strategic, tactical, and technical. Retrieved on 14/07/2021 and available at https://www.hospiq.com/blog/steps-to-improvinglength-of-stay/.

[10]Christine Chang, (2019). Intervention to decrease hospital length of stay. Available at Interventions to Decrease Hospital Length of Stay (ahrq.gov) and retrieved on 18/07/2021.

[11]Lance Robinson (2021). Care management and reducing average length of stay: connecting the dots. Available at Care Management and Reducing Average Length of Stay: Connecting the Dots | Kaufman Hall and retrieved on 20/07/2021.

[12] OECD (2021), Length of hospital stay (indicator). Doi: 10.1787/8dda6b7a-en (Accessed on 19 July 2021) and retrieved on 19/07/2021.

[13] John W. Creswell, (2003). Research Design: qualitative, quantitative, and mixed methods approaches ( $2^{\text {nd }}$ ed.). Sage publication, London.

[14](AFS) Audited Financial Statements (2018, 2019 \& 2020).
[15] Alanna-Moriarty (2011). Definitive healthcare Interactive dashboard with rich customization and self-service. Available at https://www.datanyze.com/people/AlannaMoriarty/-1049632075. [16]George Schieber et al, (2012). World Bank Report: Health Financing in Ghana at Crossroads. Available https://openknowledge.worldbank.org/handle/10986/ 2729 and retrieved on 17/07/2021.

[17] Ryan, T. P. (2013). Sample size determination and power, John Wiley \& Sons.

[18]Bryman, A, \& Bell, Emma, (2007). Business Research Methods. Oxford University Press.

[19]DeVellis R. F. (2012). Scale Development: Theory and Applications, 3rd edn. Sage, Thousand Oaks, CA.

[20]Donald R Cooper, Pamela S Schindler (2010). Business Research Methods. Tata Mc Graw Hill Education Private Limited.

[21] George H. Pink \& Louis C. Gapenski (2015). Understanding healthcare financial management $\left(7^{\text {th }}\right.$ edition). Health Administration Press, Chicago, Illinois.

[22] O’Gorman, K. \& MacIntosh, R. (2015). Mapping research methods. Goodfellow Publishers Ltd. Oxford. 